\title{
Communication
}

\section{ECCP Program in Connecticut of America and Its Enlightenment}

\author{
Zhang Li, Mengyao Chen \\ Institute of Education, Central China Normal University, Wuhan, China \\ Email address: \\ 923022942@qq.com (Mengyao Chen)
}

\section{To cite this article:}

Zhang Li, Mengyao Chen. ECCP Program in Connecticut of America and Its Enlightenment. Science Journal of Education. Vol. 7, No. 1, 2019, pp. 19-23. doi: 10.11648/j.sjedu.20190701.14

Received: December 11, 2018; Accepted: January 21, 2019; Published: May 15, 2019

\begin{abstract}
Early Childhood Consultation Partnership program in Connecticut is an important part of American children mental health consultation project. This program provides children from birth to five years old with mental health consultation service, including Child-specific Services, Core Classroom Services, and Intensive Site Services. This paper mainly uses literature method to sort out content, operation and management in ECCP program, in order to inspire children's mental health services in China. Based on the experience of Connecticut, the authors suggest that China should pay more attention to children's mental health and integrate all sources to establish a service for children's mental health.
\end{abstract}

Keywords: Early Childhood Consultation Partnership Program, Children, Mental Health Consultation

\section{Introduction}

Children's mental health problem has been translated into Children's mental hygiene problem. In general, mental health means that an individual achieves coordination in physiology, psychology and sociality, and maintains well psychological function in the process of adaptation to the environment [1]. Children's mental health points to their social emotions development, and it also involves mental health difficulties and obstacles experienced by children. Children mental health consultation refers to the establishment of a collaborative relationship between professional consultants and caregivers, typically an early care and education provider and/or family member. Early children's mental health consultation aims to build the capacity (improve the ability) of staff and families to help solve mental health problems among children from birth to age six [2].

The Early Childhood Consultation Partnership is a free mental health counseling program in Connecticut, USA that provides mental health counseling services for children from birth to age five who may be rejected by childcare settings due to mental health problems. The project enhances the mental health education capacity of stuff and caregivers by offering support, education, and consultation, which promotes the most enduring and optimal outcomes for young children.

ECCP's model includes the three core levels of service delivery: Child-specific Services, Core Classroom Services, and Intensive Site Services. These consultation services are designed on a continuum, such that one service segues into the next, broadening the focus from an individual child to a whole classroom to an entire center [3]. Despite variations in the breadth of focus, there are several common service elements that span across each level: screening/ assessment, observation, and action plan development and support.

\subsection{Child Specific Services}

Child-Specific services address the needs of a child who is exhibiting social, emotional or behavioral challenges.

Child-Specific services include screening/ assessment, classroom and in-home observation, child-specific action plan meetings to develop and refine prevention or intervention strategies, and computer-generated Child Action Plans, action plan implementation support visits. Assessments for children are generally conducted through questionnaire surveys and scales, such as the Ages and Stages Questionnaire, the 
children's version of the Sensory Profile, and so forth. While assessing children, mental health counselors will conduct an assessment of the parent, such as through the Parenting Stress Index Short Form to test. The generation of action plan has a guiding and referential role for the entire service project, including the determination of goals, participants and specific interventions. Child-specific service lasts approximately one month. Consultants also follow-up with parents and providers after the service end date to track and evaluate children's behaviors, offer additional resources or strategies if needed, and gauge satisfaction with services.

\subsection{Core Classroom Services}

Core class services mainly focus on promoting children's mental health development by building and enhancing class environment.

Core Classroom services include classroom assessment/observation, classroom action plan meetings with teacher(s) and director to develop and refine strengths-based strategies, computer-generated Classroom Action Plans, and action plan implementation support. While servicing class, the child mental health consultant will also evaluate and advise the affiliates. Similar to child assessment, the assessment of class will also use relevant scale, such as the Infant-toddler/Early Childhood Environmental Rating Scale-revised, (ECERS-r or ITERS-r), Classroom Assessment Scoring System (CLASS), etc. Consultants spend 4 to 6 hours a week providing Core Consultation services to a center and the entire class service lasts approximately 14 weeks.

\subsection{Intensive Site Services}

Intensive Site services focus on the entire center/program, including in-depth reviews, two center-wide trainings, and a center-based action plan. While carrying out the program, child mental health consultants will investigate the work beliefs and attitudes of employees of the center, and will also analyze children's mental health regulations and propose suggestions for improvement. It generally lasts 9 months.

\section{Application}

\subsection{Ways to Apply}

Different types of project have different application ways. To receive services for a child-specific service, parents or caregivers can contact the ECCP Project Corporation (ABH) by calling the toll-free helpline or contacting children's mental health consultants in the area. These contact details are available on the ECCP project website. Applications for core class service programs and intensive site service are generally submitted by the director of the care and education center, and applicants can contact the local child mental health consultant or ABH directly. Among them, application for intensive site service project must be carried out after other ECCP services have been accepted, and the director of the education institution must promise to reform.

In addition, no matter what types of services, after the application is successful, a project agreement must be signed with children's mental health consultants to clearly define the responsibilities of consultants, parents and staff, as well as the frequency and duration of services, etc.

\subsection{Reasons to Apply}

ECCP aims to promote the development of children's mental health. As long as there are factors that threaten children's mental health, parents can apply for services.

Applications for child-specific services are generally submitted by parents, teachers or the director of the care and education center. Reasons for application can be as follows: (1) Children have certain behavioral problems or developmental obstacles in certain aspects, such as anxiety, behavior disorder (biting, beating, etc.), difficulty in concentration, lack of social skills, etc. (2) Children experiences events that cause mental health problems, such as birth of younger siblings, divorce of their parents, death of loved ones, or sudden onset of natural disasters, such as storms, floods.

Applications for core class services are generally submitted by the director or teachers of the care and education center, which aims to gain support of class management such as to improve the emotional atmosphere of the class, and receive help to strengthen the cooperation of teachers, parents and managers.

Applications for intensive site services are generally filed by the director of the care and education center, but usually only centers located in urban areas or with more than 150 children can apply for this service. Applying for the program usually aims to support in how to promote children's mental health development, with a view to improving children's mental health development by cultivating employees' adaptability, team spirit, and building partnerships with families.

\section{Operation and Management}

\subsection{ECCP Project Team}

ECCP is centrally managed by Advanced Behavioral Health $(\mathrm{ABH})$ who has a professional management team for the smooth operation of the project. ECCP staff is composed of a full-time Program Manager, Assistant Program Manager, Administrative Assistant and 20 full-time Early Childhood Consultants [4], who are at the core. $\mathrm{ABH}$ has distributed 20 consultants to care and education centers in all communities in Connecticut, each with one or two consultants, thus forming an organized, systematic children's mental health counseling network.

\subsection{ECCP Children's Mental Health Consultant}

\subsubsection{Qualifications and Competency Requirements}

Children's mental health consultants are the front-line workers of the project and directly influence service quality. They must have relevant expertise and skills: First, a master's degree in public services related fields such as social work, marriage counseling, education or family therapy. Second, 
knowledge and experience of improving early child mental health.

Specifically, the essential knowledge base, skills and attributes are comprised of a set of six competencies: (1) Demonstrated knowledge and practical ability of early childhood development, mental health, and early care and education. They are able to assist early childhood staff and families in understanding typical development, addressing challenging behaviors in young children, and creating environments that foster healthy development and relationships. (2) Consultants are able to successfully engage children, families (including foster parents), caregivers (including family childcare homes), early childhood educators, and other service providers in genuine and collaborative relationships. (3) Skills of observation, screening, and data collecting. Consultants are proficient in observing behavior, interviewing adults, utilizing social and emotional screening tools, and collecting accurate and applicable information about children and their environments. Consultants are unbiased and objective in their practices of documentation, summarizing data, and reporting information. (4) Technical assistance. Consultants must have ability to collect relevant data, such as collecting children's development status, teacher quality, education environment and other data, so as to provide a solid foundation for the development of action plans, and use various consultation methods (coaching, modeling, wondering, etc.) to support the implementation of the action plan. (5) Community Partnerships. Resource sharing, service linkage, and high-quality services are the results of these partnerships. (6) Practice ability and introspection ability. Consultants' approach to every aspect of their work should be done with professionalism. Meanwhile, they need to constantly reflect on work to promote further development.

\subsubsection{Training and Assessment}

Children's mental health consultants need to be trained and tested. Training and assessment are conducted by ABH. The training mainly includes pre-service training and in-service training. The training content of each stage involves six competences, and the learning in each aspect takes 2 3 hours.

\section{(i) Pre-service Training}

It is designed to help children mental health consultants master the basic knowledge to become qualified. Pre-service training generally lasts for 6 months and includes the following six aspects: (1) An overview of ECCP program and child mental health counseling. (2) Knowledge related to child-specific service. (3) Knowledge of child development, project screening and assessment. (4) Relevant work content of core class services. (5) Assessment of early care and education center and class. (6) Knowledge of building partnerships and making effective use of resources.

\section{(ii) In-service Training}

The purpose of in-service training is to help consultants have a deeper understanding of their work and improve their service quality. It generally lasts for 18 months and includes the following six aspects: (1) Intervention strategies for infant teachers. (2) Intervention strategies for preschool teachers. (3) Children's development rules. (4) Ability to work with "at risk" people. (5) Organizational and cooperative capabilities. (6) Introspection ability.

In addition to training children mental health consultants, $\mathrm{ABH}$ also evaluates their work. The company holds a monthly consultation meeting and a group meeting every two weeks to understand working status of consultants and offer some guidance. $\mathrm{ABH}$ has established an ECCP Management Information System (MIS) to track the work of children mental health consultants and provide timely assistance if necessary. The children mental health consultant ( consultants) is also supervised and assessed by community agency while accepting the company's supervision and assessment. Compared with the institutional assessment of $\mathrm{ABH}$, the assessment of community agency is highly random with varied frequency and format but it will be implemented at least once a month.

\section{Characteristics of ECCP}

The ECCP program has developed with the increasing emphasis on children's mental health. It is a free, statewide and comprehensive program serving children from birth to age five.

\subsection{Clear Objectives, Extensive Scope of Services and Feasible Support Strategies}

The aim of ECCP is to promote the development of children's mental health from birth to five years old in Connecticut. As is known, children's mental health development is not only related to individual factors, but also related to environmental factors such as caregivers, families, peers, teachers and so on. Therefore, targets of ECCP program extend from children to parents, teachers and other caregivers. The scope of services extends from children themselves to classes and early care and education centers, with a view to promoting children's health development by improving educational capacity of caregivers and creating a good educational environment. Furthermore, the action plan and suggestions made by the program are highly practical and feasible. For example, when carrying out corresponding program service in preschool class, the transition will be fully utilized, that is, the child will be given certain hints (such as dimming the lights, playing music, etc.) to help them smoothly enter the next activity so as to not frighten them.

\subsection{Form a Unity of "Propaganda - Prevention - Intervention - Diagnosis”}

In order to meet the mental health development needs of children in an all-round way, the ECCP program has formed a unity of "propaganda-prevention-intervention-diagnosis". Propaganda is to arouse the concern of parents and other caregivers on children's mental health; prevention is aimed at children at the "risk edge" of mental health, so as to prevent 
problems before they occur; intervention and diagnosis mainly serve children who have already had psychological problems by providing necessary support to conduct psychological correction.

\subsection{Combine Unified Management with Independent Operation}

ABH provides professional support for smooth operation of the program. The professional management team focuses on transforming the program from conception to practice, thus providing guarantee for the smooth development of every service projects. The data platform can record the work process and effectiveness of children mental health consultants, and supervise and evaluate their work. While the ABH company manages the program, it also works closely with every community. The program consultant must also be supervised and assessed by the community agency at the same time. The combination of unified management and independent operation guarantees high quality and efficiency of ECCP program to a certain extent.

\subsection{Simple Application Process and Customer's Participation in Evaluation}

Program applicants can directly obtain personal information and contact details of children mental health consultants in the area on the ECCP website. If the information is not available, applicants can directly call ABH's service hotline. Moreover, applicants can submit application form on the website after filling personal information and clarifying reasons. After the program is finished, clients have right to evaluate the consultant's work, which is also a kind of supervision and assessment.

\section{Enlightenment}

ECCP in Connecticut has been improved gradually and has brought positive effects in preventing and interfering with children's mental health problems from which we learn a lot.

\subsection{Pay Attention to Children's Mental Health Problems in Theory and Conduct in-Depth Research to Improve Mental Health Awareness}

In recent years, although China has made new improvements in children's mental health research, the research perspective is still relatively one-sided and insufficient. More than 4,500 papers were searched on the theme of "Children's Mental Health", but more than $70 \%$ of them were about mental health problems of left-behind children or boarding children, while there was almost no information on children's mental health detection and prevention"; nearly over a hundred papers were searched on the theme of "Psychological Health Consultation", while there is almost no research about children's psychological counseling. Some scholars pointed out that China's research on children's mental health still focuses on the bio-medical model, and has not yet achieved the transition to a bio-psycho-social-educational integration model. Children's mental health education is often replaced by moral education [5]. As early as 1977, American scientist Engel proposed a "biological-psychological-social medicine" model to challenge the traditional "biological-medical" model [6]. Early childhood is not only a critical period of physical development, but also a critical period for mental health development. To promote the development of children's mental health in China, it is necessary to pay more attention to it and strengthen further research in this field.

\subsection{Integrate Multiple Forces in Practical and Prevent Problems}

Fully Promoting the development of children's mental health is neither easy, nor can it be done by one side only. Governments, communities, parents, and education institutions must cooperate to fully use the existing resources. Children's life circle is mainly families and schools, and the factors that lead to children's mental health problems are mainly from kindergartens and families [7]. First of all, kindergartens or other education institutions can actively carry out lectures about mental health knowledge, set up special mental health activity classes, and integrate education into activities to enrich children's necessary experience and preliminary knowledge, and prevent and solve psychological problems in a targeted manner [8]. In addition, parents and teachers should be offered training opportunities to know more about children's mental health knowledge, and learning methods such as group games, painting, behavior correction and moderate sports [9]. Studies have shown that students' psychological problems are closely related to family parenting styles and family interpersonal relationships. Some children's psychological problems are even duplicates or extensions of family problems [10]. Since family factors are closely related to children's mental health, parents can master the skills of communication with children through training, so that parents can carry out structured training for children and create a healthy family atmosphere for children's growth [11]. In addition, although the ways to promote children's mental health development are multi-faceted, it is better to prevent rather than remedy. Parents and other caregivers must have a keen observation ability to make early interventions in the course of development of children.

\subsection{Build Professional Children's Mental Health Improvement Agency to Provide Professional Services to the Public}

At present, there is no specialized government-lead children mental health consultation department in China, and children's mental health education mostly relies on kindergartens. Parents are more likely to go to a medical institution for treatment if there are obvious mental health problems. As mentioned above, children's mental health is a complex issue that involves not only children themselves, but also their intricate connections with surroundings. From 
cause investigations, diagnostic assessments to interventional treatments, multiple subjects need to participate in, especially professionals. Although making full use of existing resources such as kindergartens, families, and communities can solve problems as quickly as possible, mental health is not only a matter of life, but also a professional issue. Different psychological intervention methods need to be adopted according to the responses of different individuals to events, such as psychological counseling, supportive psychotherapy, cognitive correction and relaxation training [12]. Therefore, special children mental health consultation institutions are needed to better integrate multiple resources and professional children mental health counseling teams are necessary to effectively improve children's mental health in China.

\section{Conclusion}

In 1948, the United Nations World Health Organization clearly stated in its charter that "health not only refers to no disease or weakness, but also refers to a state of health including physical, psychological and social adaptation [13]." Health has long been more than just body health. With the development of economy, the pace of life is accelerating, the society is changing rapidly, and health in psychology has gradually become the focus of education. In the "Provisional Work Procedures for Kindergartens" issued by the National Education Commission and the "Working Regulations for Kindergartens" released officially, it emphasizes that the harmonious development of children's body and mind should be promoted and the work of physiological and mental health care for children should be done well [14] ". The "Guidelines for the Guidance of Kindergarten Education (Trial)" promulgated by the Ministry of Education in 2001 clearly stated: "Kindergartens must put the protection of the lives of young children and the promotion of young children's health at the top of their work, and establish a correct concept of health, pay attention to the health of young children. At the same time, great importance should be attached to the mental health of young children [15]." However, in the field of children's mental health, whether it is macroeconomic policy formulation or specific work operation, there are still many problems to be further studied and discussed. In the process of advancing, we must pay attention to the combination of theory and practice to promote the better development of children's mental health education.

\section{References}

[1] Cheng Minjun, Li Huarong. Health Content System and Concept Pedigree [J]. Journal of Shanxi University (Philosophy and Social Sciences), 2005 (4):30.

[2] Early Childhood Consultation Partnership [EB/OL]. [2015-05-06].http://www.eccpct.com/Program/History/.

[3] Early Childhood Consultation Partnership [EB/OL]. [2015-05-12].http://www.eccpct.com/

Program/History/.getown.edu/publications/ECMHCStudy_Re port.pdf.

[4] Early Childhood Consultation Partnership [EB/OL]. [2015-05-12].http://www.eccpct.com/About/Management-Tea $\mathrm{m} /$.

[5] Yuan Lin. Analysis of the problem of children's mental health education [J]. Journal of Shenyang Normal University: Social Science Edition, 2002, (6).

[6] Gong Jing. On the problems and counter measures of children's mental health education [J]. Curriculum Education Research, 2018 (12): 226-227.

[7] Liu Yan. Analysis and countermeasures of children's mental health problems and their influencing factors $[\mathrm{J}]$. Preschool Education Research, 2015 (03): 70-72.

[8] Wei Yonggang. On the cultivation of teachers for children's mental health education [J]. Preschool Education Research. 2005 (11).

[9] Liu Shaozhi, Chen Chong. Analysis of the Intervention Effect of Sports Games on Children's Psychological Crisis [J]. Mongolia Sports Technology, 2012, 25 (1):36-37.

[10] Da Huiming. A Review of the Research on the Mental Health of Pupils in China in the Past10 Years [J]. Journal of East China University, 2018 (06):140-144.

[11] Charach A, Carson P, Fox S, et al. Interventiona for pre-school children at high risk for ADHD:acomparative effectiveness review [J].Pediatrics, 2013, 131 (5):e1584-e1604.

[12] Liu Wen, Liu Juan, Zhang Wenxin. The development of psychological flexibility of children with psychological abuse [J]. Preschool Education Research, 2014, (3): 43-49+57.

[13] Zhu Jiaxiong. Kindergarten Course [M]. Shanghai: East China Normal University Press, 2003:80.

[14] Zhang Wei. Research on the implementation effect of an international early childhood mental health education course in Shanghai [D]. East China Normal University. 2009 (04).

[15] Ministry of Education of China. Pilot Program for Kindergarten Education [M]. Jiangsu Phoenix Education Press, 2001. 